\title{
A IMPORTÂNCIA DOS JOGOS E BRINCADEIRAS NO PROCESSO ENSINO- APRENDIZAGEM DA EDUCAÇÃO INFANTIL
}

Monica Christina Brancovan Garcia

\section{RESUMO}

Este trabalho integra os estudos da linha de pesquisa em educação e teve como objetivo principal destacar a relevância da utilização dos jogos e brincadeiras na evolução dos aspectos emocional, social, motor e cognitivo no que se refere ao desenvolvimento das crianças na Educação Infantil. A importância da temática escolhida justifica-se pelo fato que em relação ao conhecimento cientifico, todo estudo que tenha a preocupação de estudar a importância do brincar na educação infantil e que esta também associada à aprendizagem como fator relevante no desenvolvimento infantil. O presente trabalho tem como objetivo mostrar os benefícios do brincar na educação infantil. Conclui-se que as atividades lúdicas possibilitam que as crianças reelaborem criativamente sentimentos e conhecimentos e edifiquem novas possibilidades de interpretação e de representação do real.

Palavras-chave: Educação Infantil. Brincar. Aprendizagem. Desenvolvimento. 


\section{1-INTRODUÇÃO}

Diante da relevância social, econômica e política que o brincar tem na formação das crianças e mesmo com todos os problemas ocasionados pelo processo de industrialização e urbanização das cidades, além do aumento significativo dos índices de violência urbana que acabaram por tornar escassos os espaços disponíveis para as crianças brincarem livremente nas ruas, calçadas, terrenos, parques e outros pode-se constatar que as crianças não deixaram de brincar.

Sabemos que um dos últimos lugares que as crianças ainda possuem para brincar em grupos, aprendendo a conviver em sociedade, a respeitar e compreender as diferenças culturais existentes de indivíduo para indivíduo, além de diversos outros benefícios decorrentes do brincar é a escola.

A cada dia, os brinquedos e brincadeiras tradicionais vêm sendo deixados de lado pelas crianças que preferem divertirem-se utilizando artigos de alta tecnologia (videogames, computadores, brinquedos eletrônicos) que funcionam por controle remoto e fazem quase tudo sozinhos

O processo introdução da brincadeira no contexto escolar infantil, teve inicio, de forma tímida, com a criação dos jardins de infância, oriundos proposta de Froebel, cujos estudos consideram que é através de estímulos externos que a criança desperta suas faculdades próprias.

Essa idéia de Froebel serviu como base para a criação das escolas de educação infantil de todos os países.

A partir do recorte temático adotado, é possível perceber que além das características de cada época, muitos pais e até mesmo professores tem em mente que brinquedo é algo que pode ser encontrado nas prateleiras de uma loja.

No momento em que se pensa em dar um brinquedo a uma criança os pais vão até uma loja e adquirem o último lançamento da indústria dos brinquedos. Entretanto os brinquedos ali disponíveis muitas vezes refletem apenas as características de uma sociedade capitalista e consumista, já que para a criança qualquer objeto, por mais simples que seja, pode ser transformado em brinquedo bastando para isso que ela utilize a imaginação, conferindo um sentido novo ao objeto que está manipulando

Em reforço a essas considerações, vale frisar que o brinquedo e a brincadeira ajudam na prática escolar, agindo como uma ação motivadora para a criança, experimentando as necessidades onde seus desejos não realizáveis sejam supridos através do brinquedo, como um mundo real e o imaginário.

A criança vai construindo seu conhecimento de mundo de modo lúdico, transformando o real com os recursos da fantasia e da imaginação. Tem a chance de dar vazão a uma afetividade que, freqüentemente, é tolhida na difícil luta pela sobrevivência enfrentada dia a dia por seus pais.

É através da atividade lúdica que a criança se prepara para a vida, assimilando a cultura do meio em que vive, a ele se integrando, adaptando-se às condições que o mundo lhe oferece e aprendendo a competir, cooperar com seus semelhantes e conviver como um ser social.

Cabe ao professor, através do brincar, dar condições à criança para que ela adquira conhecimentos formais e para que desenvolva seu pensamento. $\mathrm{Na}$ escola se deve brincar por brincar e o professor torna-se a peça chave no processo educativo, oferecendo ferramentas no sentido de possibilitar novas aprendizagens. 
Toda a criança pode construir e ampliar conceitos através da interação de outras crianças ou indivíduos mais experientes, conceitos estes que talvez ela não teria condições de realizar sozinha.

O presente trabalho é resultado de uma vivência pedagógica diretamente relacionada a prática da utilização de jogos e brincadeiras com alunos da Educação Infantil.

\section{2- REFERENCIAL TEÓRICO}

A criança da educação infantil aprende de forma mais lúdica, através de brincadeiras, musicas, artes visuais, linguagem oral e escrita, assim, podemos explorar a imaginação e a criatividade de cada uma e descobrindo habilidades que até então era desconhecida. O estimulo ajuda no aprendizado, podendo ser usado em forma de desafios, aguçando a curiosidade, mas esse aprendizado será muito melhor aproveitado se a criança estiver em um ambiente que se sinta bem e feliz.

Segundo Kramer (1990, p.43), a Educação Infantil não se limita ao aspecto social e afetivo, mesmo sendo fatores preponderantes para o processo de ensino-aprendizagem.A autora nos diz que a organização do trabalho pedagógico na Educação Infantil deve ser orientada para o desenvolvimento da autonomia, ou seja, a capacidade de construir as suas próprias regras e suas escolhas das dificuldades apresentadas na vida social e afetiva.

Esta construção não se esgota no período de 0 aos 5 anos de idade, devido às próprias características do desenvolvimento infantil. Mas esse aprendizado necessita ser iniciado na Educação Infantil.

Continuando Kramer (1990, p.46) ressalta que a, Educação Infantil tradicional não procura desenvolver a autonomia, mas sim a heteronomia, ou seja, a dependência, da criança, de regras e meios de ação ditados pelo adulto. A autora afirma que a escola tradicional, que impõe as regras de convivência sem discuti-las com os educandos, reforça a sua dependência do adulto, já que a heteronomia é característica do pensamento das crianças de 0 a 5 anos. Certamente, este não é o melhor modelo pedagógico, se pretendemos o desenvolvimento integral e a construção da autonomia infantil.

Para que a criança possa alcançar estes objetivos o modelo pedagógico deve proporcionar-lhe situações em que ela possa vivenciar as mais diversas experiências, fazer escolhas, tomar decisões, socializar conquistas e descobertas. Vale ressaltar que não se trata de um trabalho espontaneista, onde o adulto não organiza objetivamente as atividades oferecidas às crianças, assumindo um papel de mero espectador, que observa e espera o desenvolvimento dos pequeninos. (KRAMER, 1990, p. 63)

As crianças, em interação com o meio, se desenvolvem e constroem seus esquemas perceptuais, motores, cognitivos, lingüísticos e sua afetividade, ao se apropriar das experiências de seu grupo social. Essas trocas de experiências com outras crianças e com o meio ambiente possibilitam o desenvolvimento pessoal e cultural da criança, sendo fundamentais ao processo de formação infantil.

\section{2-1 A EDUCAÇÃO INFANTIL: TEMPO E ESPAÇOS EDUCATIVOS}

A Educação Infantil vem adquirindo importância crescente nos debates a respeito da política educacional brasileira. 
A teoria froebeliana, ao considerar o brincar como uma atividade espontânea da criança, concebe suporte para o ensino e permite a variação do brincar, ora como atividade livre, ora orientada. (WALTER, 1989, p.21) As concepções froebelianas de educação, homem e sociedade estão intimamente vinculados ao brincar.

Froebel introduz o brincar para educar e desenvolver a criança; sua teoria metafísica pressupõe que o brincar permite o estabelecimento de relações entre os objetos culturais e a natureza, unificado para o mundo espiritual. Assim, o brincar como atividade livre e espontânea, é responsável pelo desenvolvimento físico, moral, cognitivo, os dons ou brinquedos, objetos que subsidiam atividades infantis.

Entende também que a criança necessita de orientação para o seu desenvolvimento, perspicácia do educador levando-a a compreender que a educação é um ato institucional que requer orientação. (WALTER, 1989, p.25)

O professor no seu papel de mediador, deve proporcionar situações em que as crianças possam desenvolver suas habilidades. Para isso, ele precisa saber o que atingir, qual é o seu objetivo perante a turma de alunos com que vai trabalhar. Muitas vezes, encontramos professores que vêem o brincar de forma equivocada, encaram este somente como recreação, sem um planejamento que interage essa atividade com as demais.

Segundo Magalhães (2002, p.74), consideram a criança como um organismo que cresce quase como uma planta, com a implicação de que contem, em si, a semente do adulto. Nesse caso, a tarefa dos pais e dos professores consiste apenas em fornecer o meio adequado para que essa semente possa florescer. Ainda segundo o mesmo autor "o educador deve desenvolver uma relação afetiva com as crianças e favorecer desenvolvimento de sua autonomia, deixando-a exercer sua vontade tanto quanto possível".

Segundo Kramer (1990, p.53), o papel do profissional é essencial na criação de um ambiente rico, prazeroso, saudável e não discriminatório, de experiências educativas e sociais variáveis. Sabemos que a brincadeira é uma ação que ocorre no plano de imaginação, que tem domínio da linguagem simbólica.

A realidade imediata fornece, portanto, o conteúdo para que a criança, dando-lhe significado, consiga, através da brincadeira, transformar essa realidade "por ela apropriada" em uma ação imitativa onde suas emoções e idéias possam ser exteriorizadas. Assim, poderá interagir com a criança representando um personagem mediando informações para que as crianças possam refletir e construir seu conhecimento. A brincadeira propicia a autoestima da criança auxiliando-a a superar progressivamente suas aquisições de forma criativa, vem como a resolução de problemas.

Ainda de acordo com Kramer (1990, p.55), o professor pode utilizar um momento da brincadeira para investigar seus alunos, prestando atenção às maneiras como as crianças organizam suas brincadeiras escolhem os papeis que vão representar, dos gestos e palavras que vão desenvolver, quais os materiais que vão utilizar para brincar.

É importante a observação do adulto diante das situações vividas pela criança. Ele precisa estar disposto a conversar, intermediar e levantar problemas para que as crianças exercitem suas habilidades de criar situações e reflexão. É preciso que o educador esteja atento às falas, gestos, escolhas, atitudes e produções das crianças. O professor, por sua vez, estará servindo de intermediário e colaborador, tornando seu trabalho mais completo e tendo uma visão mais amplas sobre cada um de seus alunos. Assim, poderá preparar situações pedagógicas diversas 
de acordo com as necessidades de cada criança, para colaborar com sua infância de descobertas, alegria e superação.

Kramer (1990, p.58), afirma que por meio das brincadeiras os professores podem observar e constituir uma visão dos processos de desenvolvimento das crianças em conjunto e de cada uma em particular, registrando suas capacidades de uso das linguagens, assim como de suas capacidades socais e dos recursos afetivos e emocionais que dispõem. Sendo assim, a educação mais eficiente para as brincadeiras são aquelas que proporcionam atividades, auto expressão e a participação social, neste sentido a escola deve considerar a criança como atividade criadora e despertar, mediantes estímulos às faculdades próprias para a criação produtiva.

Kramer (1990, p.59), enfatiza que o educador deve fazer do lúdico uma arte, um instrumento para facilitar a educação da criança e a melhor forma de conduzi-la à atividade, autoexpressão e a socialização por meio do método lúdico. A intervenção do professor é necessária para que, na instituição da educação, as crianças possam, em situações de interação social ou sozinha, ampliar suas capacidades de apropriação dos conceitos, dos códigos sociais e das diferentes linguagens, por meio da expressão, elaboração de perguntas e respostas, da construção objetos e brinquedos. Para isso, deve conhecer e considerar as singularidades das crianças, assim como a diversidade de hábitos, respeitando suas diferenças e ampliando sua socialização. Portanto, o professor é mediador entre as crianças e os objetos de conhecimento, propiciando espaços e situações de aprendizagens que articulem os recursos e capacidades afetiva, sociais, e cognitivas de cada criança.

Nesta perspectiva na instituição de educação infantil o professor constitui-se, no parceiro mais experiente, por excelência, cuja função é propiciar e garantir um ambiente rico, prazeroso, saudável e não discriminatório de experiências educativas e sociais variadas.

\section{CONSIDERAÇÕES FINAIS}

Diante da relevância no ambiente de ensino, social e cultural que assume a as brincadeiras para o desenvolvimento da criança na Educação Infantil em um mundo marcado pelo constante desenvolvimento e aprendizado constante; em que os meios de ensino assentam-se em constantes mudanças e melhorias e sua divulgação e compartilhamento ocorrem em maior velocidade em todas as ocorrências, desta forma todos os meios que possam ser utilizados pelas escolas e, sobretudo, pelos docentes, em beneficio ao desenvolvimento na Educação Infantil e na luta para uma melhor educação, são bem-vindos.

Por estarem presentes no cotidiano na fase da educação infantil e fazer parte do desenvolvimento da criança em seu sentido mais amplo, as brincadeiras são dotadas da grande poder de aprendizado, ao longo dos tempos, o brincar foi s modificando e as brincadeiras se alteraram, no entanto seu beneficio e efeitos continuam a beneficiar a criança e facilitar o oficio do educador de transmitir conhecimento.

Confirmamos, pois, diante dos estudos realizados acerca dos aspectos e efeitos do brincar para o desenvolvimento da criança na educação infantil, por ser dotado desenvolvimento lúdico, cognitivo, social e racional torna-se um meio didático rico para se trabalhar com crianças na educação infantil onde a brincadeira é uma atividade atrativa..

Além do mais, o caráter lúdico das brincadeiras contribuem para a promoção da criatividade e imaginação da criança trabalhando com conhecimento novos ou exercendo e praticando os já 
neste sentido, torne-se uma atividade caracterizada pela interação social onde não somente a criança brinca mas pode se relacionar com diversas outras crianças, convidando para seu intimo e mundo criado a partir de sua vontade.

Este contento possui fácil localização, podendo ser consultado e localizado em sites, livros didáticos e mesmo na observância do cotidiano das crianças que naturalmente brincam e interagem de forma lúdica com brinquedos ainda consultada pelos próprios professores e alunos que estão em constante contato com as crianças, as brincadeiras, em face do exposto, transformam-se em poderosos auxiliares didáticos para que o educador possa efetivar sua tarefa de ensinar, é um facilitador que convida a criança a uma atividade que encontra familiaridade, lazer e conforto

No entanto, enfatizamos a necessidade de o educador e profissional de ensino manter constante capacitação, treinamentos e estudos para que possa oferecer melhor educação para as crianças na educação infantil assim conhecer a fundo o gênero com que irá trabalhar e seus benefícios para poder tirar o melhor rendimento e proveito de ensino, assim não subaproveitá-lo com práticas docentes estereotipadas, mecanicistas e limitadoras, onde as crianças apenas crianças isoladas sem desenvolver suas capacidades.

\section{BIBLIOGRAFIA}

KRAMER, Sônia. Infância, cultura contemporânea e educação contra a barbárie. São Paulo: Cortez, 2003.

MAGALHÃES, Celina Maria Colino; PONTES, Fernando Augusto Ramos. A estrutura dabrincadeira e a regulação das relações. Psicologia: Teoria e Pesquisa, Brasília, v. 18, n. 2, p. 213-219, Mai./Ago. 2002.

A transmissão da cultura da brincadeira: Algumas possibilidades de investigação, Psicologia: Reflexão e Crítica, Porto Alegre 2003, v. 16, n.1. Disponível em: http://www.scielo.br/pdf/prc/v16n1/16803.pdf. Acesso em: 06 de janeiro de 2020

WALTER, Benjamim. Reflexões: A criança, o brinquedo, a educação. Summus editorial, $2^{\text {a }}$ ed, 1989 